\title{
GPS-Based AR Games Development Potential
}

\author{
Gregorius Alvin Raditya Santoso \\ Department of Information Systems, Soegijapranata Catholic University \\ gregoriusalvin24@gmail.com
}

\begin{abstract}
The application of new technologies in a game is not a new thing. One example is the application of Augmented Reality (AR) technology in game. Many people do not know the application of AR technology in game, although the application of this technology is able to produce a game with unique gameplay. In addition, since AR game is GPS-based, it offers new gaming experience, that is, playing outdoors in which the real world becomes the game arena. This advantage gives the AR technology a huge potential to be developed into a game.
\end{abstract}

Keywords- Game, Augmented Reality, Virtual Reality

\section{INTRODUCTION}

Technology continues to develop rapidly, but there are still many people who are able to catch up with its full speed. Gaming world is also highly influenced by technological development. Many game developers attempt to apply new technologies for innovations in a gaming world. One example is Augmented Reality which is well known as AR. AR technology is used in various sectors, like design, business, advertising, and game. It is a technology which combines objects in virtual world with those in real environment. This technology allows us to see the real world with different perspectives, because the world we see is equipped with a projection of the virtual world object.

Application of this technology in game enables gamers to have different gaming experiences when playing games. This is because the game arena is the real world the gamers live in, yet equipped with a projection of the virtual world. For offering different and "realistic" experiences, the AR technology has a huge potential to be applied in a game.

\section{LITERATURE REVIEW}

\subsection{Definition of Game}

The followings are some experts' definitions of Game:

\section{a. For John Naisbitt}

Game is a dynamic participatory system because it contains a level of narration not existing in film.

b. For Fauzia A

Game is a form of entertainment that is often used as a mind refresher from fatigue caused by our activities and routines.

c. For Albert Einstein

Game is the highest form of investigation.

\subsection{Types of Game}

Types of game can be distinguished by associating abilities and skills relating to learning and education (Aguilera \& Mendiz, 2003), such as :

1. Arcade and Platform Game can be an instrument for developing psychomotor learning and spatial orientation.

2. Sports and dynamic game can ease psychomotor coordination and reduce stress.

3. Strategy and role game can help to stimulate motivation from within and have a reflection of the value of the game. 
Puzzle and question game can help to develop the ability for reasoning and logical thinking.

\subsection{Virtual Reality \& Augmented Reality}

Virtual reality is composed of an interactive computer simulation, which senses the user's state and operation and replaces or augments sensory feedback information to one or more senses in a way that the user gets a sense of being immersed in the simulation (virtual environment).We can thus identify four basic elements of virtual reality: the virtual environment, virtual presence, sensory feedback (as a response to the user's actions) and interactivity. (Sherman WR \& Craig AB, 2003)

Augmented Reality (AR) is a variation of Virtual Environments (VE), or Virtual Reality as it is more commonly called. VE technologies completely immerse a user inside a synthetic environment. While immersed, the user cannot see the real world around him. In contrast, AR allows the user to see the real world, with virtual objects superimposed upon or composited with the real world. Therefore, AR supplements reality, rather than completely replaces it. (Ronald Azuma, 1997)

\section{RESEARCH METHODOLOGY}

- Literature Study

Author read some relevant sources on games, Augmented Reality and Virtual Reality for gaining more knowledge.

- Questionnaire

Author distribute online questionnaire containing 25 questions to some respondents from various circles to find out public opinion about the potential of GPS-based AR games development.

\section{RESULTS AND DISCUSION}

Compared to other gaming technologies, AR technology has not been widely known. However, the result of the questionnaire shows that as many as $67.6 \%$ of respondents know about the AR technology. The reason is that in order to gather information about AR game potential, the author necessarily seeks respondents who have already known about these technologies. There are as many as $11.8 \%$ having heard about the AR technology, and as many as $20.6 \%$ who do know about the AR technology. The technology is less familiar probably due to its lack of application in daily life.

Through questionnaires distributed, more information is obtained, and one of which is the factor that makes the AR games less popular in the community. There are two main factors, namely, the lack of enthusiasts and gamers meet difficulties to play the AR games. Both of these factors are brought up by $30.8 \%$ of respondents. While as many as $19.2 \%$ of respondents point out that the system requirements for game are quite high as a factor hindering AR games to be popular. That the AR games are uninteresting is chosen by $7.7 \%$ of respondents. As many as $11.5 \%$ choose suggest other factors.

GPS-based AR game enthusiasts tend to be interested in playing it because the gameplay it offers. As many as $44 \%$ of respondents choose this reason, while $16 \%$ of respondents are interested because it uses the new technology, the AR. Other influential factors are an invitation from a friend to play that game and a graphical display. These two factors are chosen by $8 \%$ of respondents each. As many as $24 \%$ of respondents have other reasons to play the GPS-based AR games. The gameplay factor was the main attraction. This is because the GPS-based AR games make the real world as the game arena itself. Gameplay usually invites gamers to have physical movements and roam the real world.

When playing the game, $66.7 \%$ of respondents experience problems, such as the failure of GPS failed to lock up or internet quota is already used up. A total of $39.1 \%$ of respondents experiences problem with their 
GPS, while as many as $30.4 \%$, their used-up internet. Other problems are confusing gameplay chosen by $8.7 \%$ of respondents, and quite high system requirements of the game chosen by $4.3 \%$ of respondents. Of course the most important thing in playing the GPS-based AR games is GPS working well. Therefore it is not surprising if the failure of GPS to lock up becomes a problem.

Compared to other console/PC games without AR technology, GPS-based AR games have comparative advantages in terms of social interaction and portability. These two factors are chosen by $34.6 \%$ of respondents. A total of $15.4 \%$ of respondents chooses the gameplay factor, and game graphics factor is only chosen by $3.8 \%$ of respondents. The rest choose other factors. Whereas when compared to android / iOS game without AR technology, GPS-based AR games is superior in terms of gameplay and social interaction. As many as $50 \%$ of respondents choose social interaction and $34.6 \%$ of respondents, the gameplay. And in terms of system requirements and game's graphics each chosen by $3.8 \%$ of respondents. These data demonstrate that when compared to other games without AR technology, GPSbased AR games have an advantage in social interaction.

The drawback of GPS-based AR games when compared with console / PC game without AR technology is in their graphics. As many as $48 \%$ of respondents choose the graphics, while $16 \%$ of respondents choose the gameplay as the reason why $\mathrm{AR}$ game is inferior to games in general. Both portability and social interaction factors are chosen by $8 \%$ of respondents each. As many as $20 \%$ of respondents choose other factors as the cause of the AR games shortcoming. When compared to android / iOS game without AR technology, the major drawback of AR games lies in the graphics and system requirements. A total of $30.8 \%$ of respondents choose the graphics, while $26.9 \%$ of respondents, the system requirements. The rest of the respondents choose the gameplay (19.2\%) and social interaction (11.5\%). As many as $11.5 \%$ of respondents choose other factors.

GPS-based AR games, in fact, don't heavily rely on graphic for attractiveness. Usually they only count on unique gameplay. Additionally, for the time being, the system requirements needed to play the game ARbased GPS is also quite high if compared to common android / iOS game.

Apart from being a medium of entertainment, it turns out that GPS-based AR games give influence to gamers' social lives. A total of $69.2 \%$ of respondents state that GPSbased AR games affect their social life. In addition, 56\% of respondents claim that GPSbased gaming AR gives them benefits. Some benefits offered by GPS-based AR games are to increase ones' knowledge about their surroundings, to become a means of socialization, and of exercise as well. This is because when playing GPS-based AR game, gamers should be in open area or outdoor that would require their physical activities such as walking. , Playing the game also means socializing with other gamers. One obvious concern when playing the game is the lack of attention to surrounding. There is a possibility that gamers are less concerned with their circumstances since they might focus more on the game being played.

Gaming world is not free from fraud, and it can be the case for GPS-based AR games. Fraud usually takes forms in gamers' creation of fake accounts and spoofer (changing the GPS lock area). As many as $50 \%$ of respondents say that they have ever encountered fraud in the form of spoofer while $12.5 \%$ experiences fraud in the form of fake accounts. This fraud can be overcome by the game developer by blocking the fake accounts and by blocking gamer performing unnatural GPS movement. In addition, the player reporting system which is applied to the game can also decrease the fraud. However, game developers have to consider several things in the application of player reporting system in 
order to avoid blocking the gamers not engaging in fraud.

GPS-based AR games are something new in the gaming world. Therefore, game developers should be able to expose the AR technology applied to their game to the public. By doing so, people will have a better knowledge of AR technology. Based on the questionnaire, GPS-based AR games are potential to be developed in several ways. The most prominent potential for development is in terms of gameplay and game events. For further development of GPS-based AR games, $40 \%$ of respondents choose the gameplay, $32 \%$ of respondents choose the game events, $12 \%$ of respondents choose graphics, and $8 \%$ of respondents choose social interaction. The rest suggest other aspects.

Of course, GPS-based AR games have the potential to continue developing in the gaming world as long as game developers keep making innovations. Innovations can be in forms of adding more realistic game events, such as gathering gamers somewhere and adding up more game events in the game. Game developers also need to make a more interesting gameplay, so that the gamers won't be easily bored. The game's display should be interesting, and at the same user-friendly especially for novice gamers. Another important thing is that game developers should be able to make a clear tutorial on how to play the game. A good tutorial on GPS-based AR games is badly needed since the AR technology is still rarely applied in the gaming world.

\section{CONCLUSIONS}

Up to this moment, Augmented Reality (AR) game have had limited enthusiasts. This is because the AR technology is still unfamiliar to the general public. GPS-based AR game actually has a huge potential to be developed, especially in terms of gameplay and game events. However these aspects should go hand in hand with more game developers' publications of the AR technology for public education. As it is explained before, the application of AR technology in a game in fact can offer new game playing experiences and social interactions among gamers.

\section{REFERENCES}

[1]https://carapedia.com/pengertian_definisi_g ame_in fo2144.html, accessed on 28 August 2014

[2]http://www.cs.unc.edu/ azuma/ARpresence .pdf, accessed on 1 August 2014

[3]http://www.etunas.com/web/teorigame.htm, accessed on 1 August 2014 [4]http://www.researchgate.net/publication /274312287_Kajian_Virtual_Reality, accessed on 1 August 2014 